\title{
OPTIMIZATION OF QUALITY, ENVIRONMENTAL AND OCCUPATIONAL RISK BY THE SYSTEM AND TECHNOLOGICAL SOLUTIONS
}

Tatiana Karkoszka

Silesian University of Technology, Gliwice, Poland

E-mail: tatiana.karkoszka@polsı.pl

\begin{abstract}
The purpose of the research has been preparation of the univocal methodology of integrated risk management and usage of the system and technological solutions as a manner of quality, environmental and occupational risk optimization. The methodology used for the analysis has included a proposition of system, technological and cost aspects of integrated risk management. Particularly the methodology management should be based on the optimization of the risk and realized as the integrated operational control as well as on the monitoring of integrated system risk. Findings of the research, which have been conducted on the basis of the prepared methodology, are as follows: one of the manners of the integrated risk reduction is application of the univocal method of integrated risk estimation, which should be specific for the organization. Results of the integrated analysis should be a starting point for the minimization of the integrated risk by assuring processes continuity both on organizational and technological level. Practical implication, confirmed in the chosen production organization, can be applied in case of any organization, which wants to manage the integrated risk in the complex meaning of clients' requirements, natural environment protection and safety conditions assurance.
\end{abstract}

Key words: environment, integration, occupational safety, quality, risk management.

\section{Introduction}

Nowadays the system approach to management creates in the organization the opportunity to comply with clients', workers' and interested sides' requirements being the best and accepted by all of the stakeholders manner of aims realization. The essence of system quality, environmental and occupational safety management is the conception of continuous improvement of all of the realized processes in the meaning of their conformity, effectiveness and efficiency. The main aim of the systems is the identification of the real and potential threats and the prevention of their effects occurrence. Therefore it's possible to integrate the requirements connected with quality assurance, minimization of the environmental aspects and impacts and elimination of occupational threats by the implementation of the integrated management system described by exclusively one: politics, manner of aims determination and supervision of documentation, procedure of corrective and preventive actions, system of audits and trainings.

However practice of the organizations confirms that the integration of management systems is limited to the general system solutions. Processes which are orientated towards the direct realization of quality, environmental and occupational aims remain in the competences of different organizational units. Very often the reason of the non-integration of the management systems is the absence of the coherence in operational criterion.

Quality management uses tools and methods of data gathering and processing, which when used in the comprehensive way - allow for realize the processes in the supervised way. From the point of view of risk assessment the methods of the key importance are expert (e.g. 
PROBLEMS

OF MANAGEMENT

IN THE $21^{\text {st }}$ CENTURY Volume 6, 2013

FMEA) and statistical methods strongly aided by traditional quality management tools. In the context of environmental management, according to the aim of minimization and elimination of negative environmental impact, risk assessment methods are used for effectiveness evaluation of natural environment protection. They allow for the verification of the planed pro-ecological activities both in the system and the operational meaning, and - as the effect - for monitoring and minimization of ecological risk connected with occurrence and significance of environmental aspects and impacts. It is possible to differentiate three groups of environmental risk assessment methods. These are methods resulting from legal requirements (e.g. safety report of Seveso II directive), environmental standards of utility character (e.g. assessment of environmental activity effects) as well as of the direct need of determination of the probability of environmental impacts occurrence their significance for the environment. Occupational health and safety management uses methods of occupational risk assessment, which allow for minimization of the risk of occupational illnesses and accidents at work. Both quantitative and qualitative methods are used in the organizations, but the widespread methods are: Risk Score, HAZOP, FTA and PHA.

Thus the identification of the threats, their assessment and prevention of the effects is usually realized in the specific way even in the integrated management system.

\section{Methodology of Research}

\section{Research Instrument}

Both the limited possibilities of standardized systems integration and the turbulent character of internal and external conditions of organizations' functioning are favorable for new trends in the processes optimization. In this context it seems to be necessary to seek a tool, which would allow to fulfill all the integrated legal requirements by elimination the processes' threats and their effects perceptible by all the stakeholders. As a manner of improvement solution a risk management has been proposed.

The risk management should have a system character by concerning all the realized processes, involving all the employees, using all the resources and being the subject of optimization as the effect of conformity assessment, monitoring, measurements and analyzes.

\section{Research Design}

On all of the levels of processes realized in any organization the knowledge of the risk describing those processes minimizes the probability of non-fulfillment of their aims and, if it is necessary, it shows the points of indispensable optimization. It can be accepted that the risk management based univocally on the "process approach" relates to three levels of organization activities: management system processes, operational processes and tactical processes (Figure $1)$.

The ground of risk management must be always risk assessment. The identified threats are the subject to analyzes, estimation of risk level as well as to assessment of risk acceptability. The applied risk estimation method must be dependent on the process defined earlier as the system or operational one. The results of risk acceptability assessment are the basis of risk optimization, which can be realized as the system or technological one.

Selection of the risk assessment method must be dependent on its tactical, operational and system range and its appliance should assure objective results. Therefore in the proposed risk estimation usage of both quantitative and qualitative methods is required. 


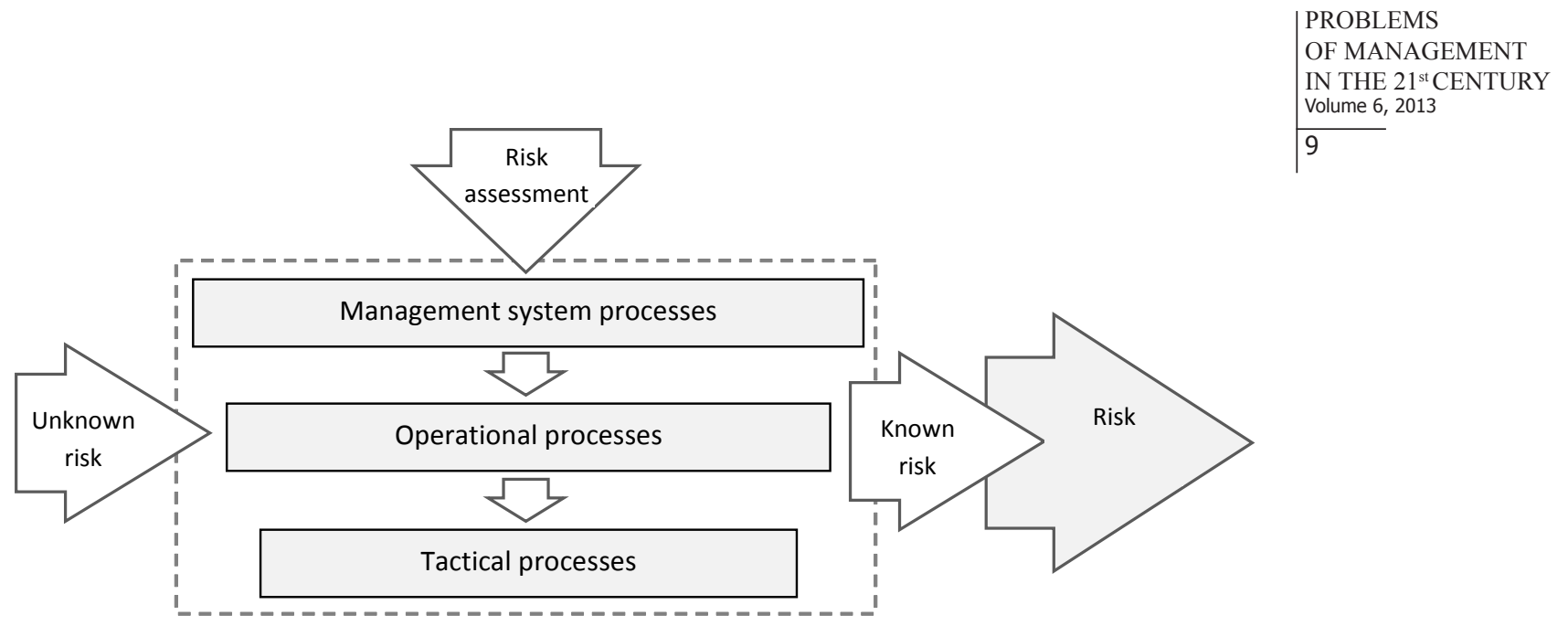

Figure 1: Scheme of the risk management based on the „process approach" on
the system, operational and tactical level of organization activities.

Character of tactical risk, in most cases, can be described as objective one. Therefore algorithm of integrated risk assessment is summarized by calculation of the Integrated Risk Ratio (IRR) value, which reflects the probability of incompatibilities causes and significance of their effects. Probability of occurrence of causes of nonconformities, environmental aspects and occupational safety threats as well as significance of nonconformities, environmental aspects and occupational safety threats effects are expressed in the ten-step scale. Integrated Risk Ratio is constituted by the sum of risk ratios in the quality, environmental and occupational safety range. Definition of the operational processes described by IRR of very high values seems to be a starting point to their optimization.

The nature of the risk in the integrated management system is usually subjective. Therefore in reality it's difficult to evaluate it by direct measurement, but it is possible to implement the system management and assessment of the risk. The system has a character of the requirements based on the quality, environmental and occupational criterion and integrated by the risk and can be applied by any organization independently on its size and kind of the realized processes effective planning, implementation and improvement of all activities minimizing the risk of the processes. The basis of system risk evaluation is giving the answers for the risk questions classified in five main categories of the system risk. Level of system and operational risk acceptance is determined by the organization.

The accepted by the organization clear method of risk identification and evaluation creates the grounds for the manner of risk management. According to the proposed methodology management should be based on the optimization of the risk and realized as the integrated operational control as well as monitoring of integrated system risk.

The integrated operational control includes the definition of the operational criteria and operational attributes. Based on the risk assessment and using the Integrated Risk Ratio activity allows for identification of the key incompatibilities creating the main process' risk value. Scheme of the feedback realized as the operational control based on quality, environmental criterion occupational safety has been shown on Figure 2. 

OF MANAGEMENT
IN THE $21^{\text {st }}$ CENTURY Volume 6, 2013

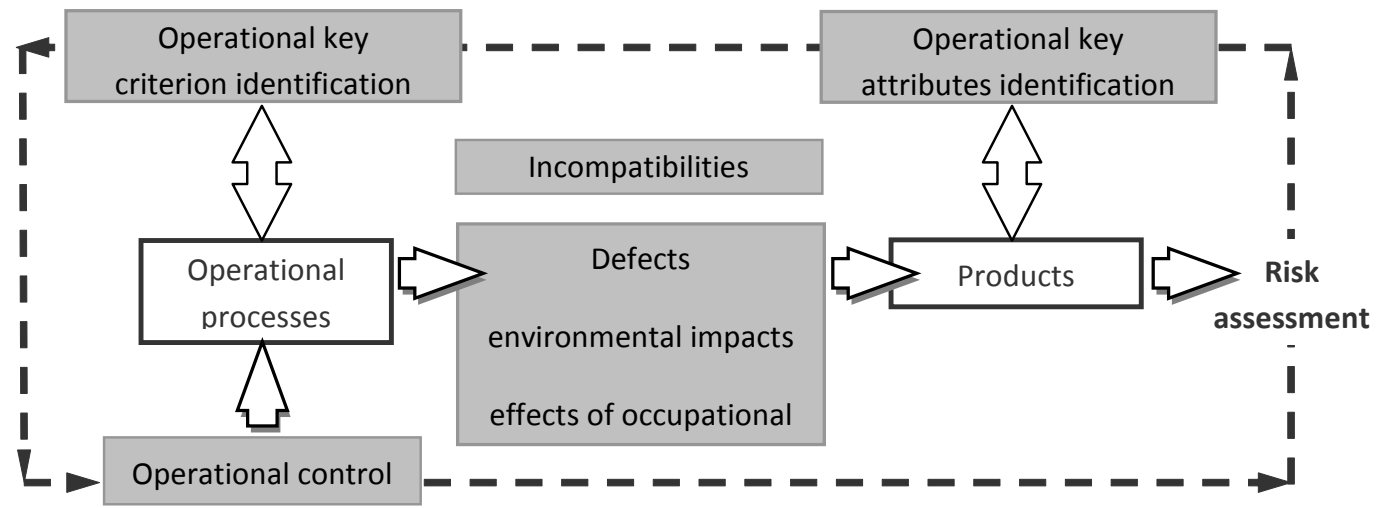

Figure 2: Scheme of operational control based on quality, environmental and occupational safety criterion.

The range of system monitoring, being a manner of system risk management, is dependent on the risk categories and subcategories defined by the organization. Each category of the risk is characterized by the significance of the realized processes for the minimization of the system risk. Main categories of the system risk monitoring used in the analyzed organization has been shown on Figure 3.

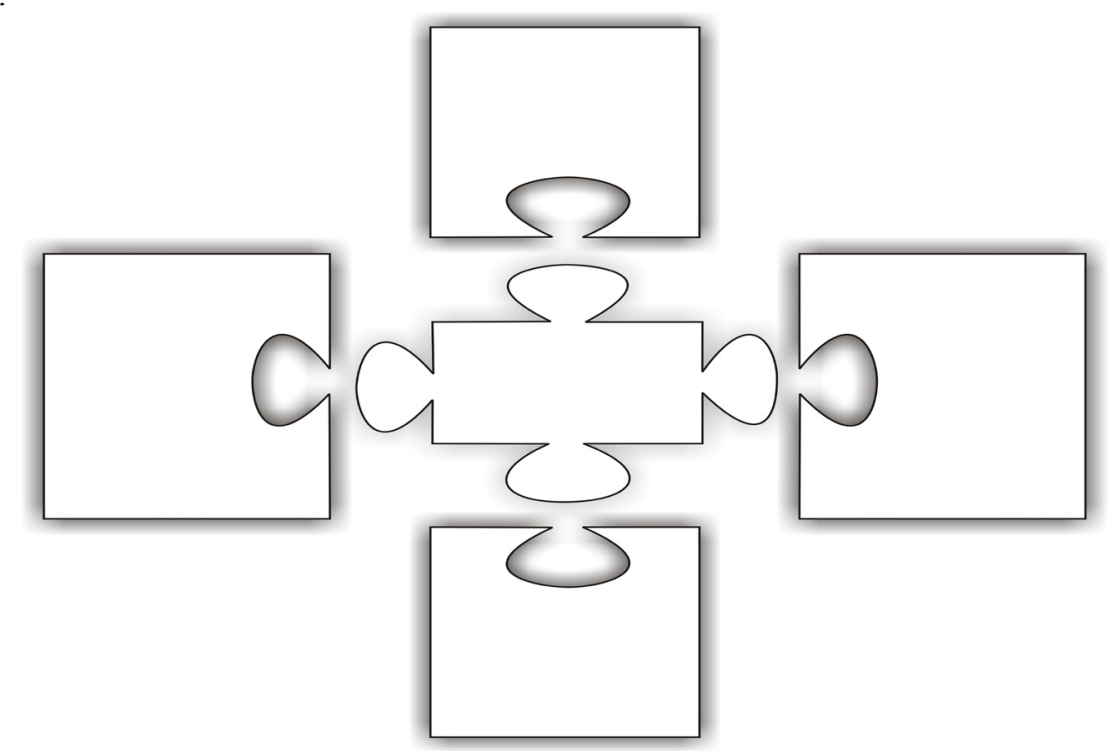

Figure 3: Scheme of main categories of system risk monitoring.

\section{Sample of Research}

The integrated optimization of quality, environmental and occupational risk was carried out in chosen organization with usage of the designed research methodology based on the integrated risk assessment and operational control as well as integrated audit and system monitoring.

Main process realized by the organization, being the subject of analyzes, is DPF production. Diesel particulate filter (DPF) is now treated as the best outside engine method of the limitation of particulates emission used in the exhaust system of high-pressure engines. The 
particulate filters produced in the analyzed organization are round and as the right filter material silicon carbonate is used. The production process consists of: preparation of the mixture, its

kneading and molding, plugging holes in the segments, firing the segments, pasting and cutting the blocks and finally firing and drying the filters.

The designed research methodology of risk management was used in the described production process. Optimization of quality, environmental and occupational risk was realized both by the technological and system solution. The application of the re-use of the production wastes was aiming at the elimination of the environmental effects and production costs and the system operational control aimed at minimizing the probability of incompatibilities occurrence in the operations realized in the supervised conditions.

\section{Results of Research}

On the operational level during the integrated risk estimation the usage of Integrated Risk Ratio was the basis for classification of the processes dependently on the risk level and undertaking the activities aiming at the risk optimization (Table 1).

Table 1. Specification of the processes'IRR values before and after the optimization.

\begin{tabular}{|c|c|c|c|}
\hline $\begin{array}{l}\text { Process and minimal level of IRR assur- } \\
\text { ing their acceptance }\end{array}$ & \multicolumn{3}{|c|}{ IRR value and risk of processes depending on it } \\
\hline \multirow[b]{2}{*}{$\mathrm{IRR}=0$} & \multicolumn{3}{|c|}{ Acceptable } \\
\hline & Acceptable & if the defined & Unacceptable \\
\hline Preparation of the mixture & $\mathrm{IRR}_{2}=174$ & & $\mathrm{IRR}_{1}=248$ \\
\hline Molding & $\mathrm{IRR}_{2}=162$ & & $\mathrm{IRR}_{1}=279$ \\
\hline Plugging holes in the segments & & $\mathrm{IRR}_{2}=202$ & $\mathrm{IRR}_{1}=202$ \\
\hline Firing the segments & $\mathrm{IRR}_{1}=178$ & & \\
\hline Pasting and cutting the blocks & $\mathrm{IRR}_{1}=84$ & & \\
\hline Firing and drying the filters & $\mathrm{IRR}_{1}=182$ & & \\
\hline
\end{tabular}

Specification of the costs of production with and without the application of the technological optimizing solutions has been shown in Table 2.

Table 2. Specification of the production costs with and without minimizing risk solutions.

\begin{tabular}{lllll}
\hline \multirow{2}{*}{ Process } & \multicolumn{2}{l}{ The average cost of materials for the mixture [€] } & \\
\cline { 2 - 5 } & Lot of material & Twenty-four hours & Month & Year \\
\hline $\begin{array}{l}\text { With risk } \\
\text { Minimizing solutions }\end{array}$ & 1160 & 290115 & 5802312 & 69627744 \\
\hline $\begin{array}{l}\text { Without risk minimizing } \\
\text { solutions }\end{array}$ & 1200 & 301428 & 62028572 & 72342864 \\
\hline Differences & 40 & 11313 & 226260 & 2715120 \\
\hline
\end{tabular}


PROBLEMS

OF MANAGEMENT

IN THE $21^{\text {st }}$ CENTURY Volume 6, 2013

The results of the system monitoring realized as the element of risk system and traditional system auditing in the analyzed organization have been shown in Table 3.

Table 3. Specification of the results of the system monitoring realized in the organization and the minimal values of processes' efficiency on the improvement levels of the chosen range of system monitoring as an example as well as the traditional system auditing.

\begin{tabular}{|c|c|c|c|c|c|}
\hline \multirow{3}{*}{$\begin{array}{l}\text { Risk system } \\
\text { category }\end{array}$} & \multicolumn{5}{|c|}{$\begin{array}{l}\text { Minimal values of risk system efficiency } \\
\text { and effects of system monitoring and auditing }\end{array}$} \\
\hline & \multicolumn{4}{|c|}{ Degree of requirements' fulfilment [\%] } & \multirow{2}{*}{$\begin{array}{l}\text { Incompatibilities } \\
\text { in the integrated } \\
\text { system [number] }\end{array}$} \\
\hline & Year 2011 & Year 2012 & Level 0 & Level 1 & \\
\hline $\begin{array}{l}\text { Management commit- } \\
\text { ment }\end{array}$ & 65 & 68 & 65 & 70 & 0 \\
\hline Resource assurance & 70 & 72 & 70 & 75 & 1 \\
\hline $\begin{array}{l}\text { Process realization } \\
\text { - operational control }\end{array}$ & 72 & 75 & 75 & 80 & 3 \\
\hline $\begin{array}{l}\text { Measurement, analysis, } \\
\text { monitoring }\end{array}$ & 74 & 78 & 75 & 80 & 2 \\
\hline
\end{tabular}

\section{Discussion}

By the lowest values of the Integrated Risk Ratio $\left(\operatorname{IRR}_{1}\right)$ processes of firing the segments, basting and cutting the blocks were characterized. The highest values of the $\mathrm{IRR}_{1}$ were calculated for preparation of the mixture, its molding and plugging the holes in the segments. The minimal level of the integrated risk ratio to find a risk as acceptable one the organization defined on the basis on its own experience and according to the accepted ALARP rule. The optimization of quality, environmental and occupational risk means making the risk as low as reasonably practicable. It is not the smallest one, but the optimal one with the consideration of risk minimization costs. As a range of risk acceptability the organization indicated $I_{R R}$ of 200 value. Under the assumed acceptability rule all of the processes being described by the $\operatorname{IRR}_{1}$ values higher than the acceptable one were qualified to risk optimization processes.

Analyzes of the plugging holes in the segments revealed the instability of the process being a result of the human influence on conformity assurance. In this case the use of the operational control proved to be sufficient in the maintenance of the conditions of the supervised risk. The determined level of $I_{R} R_{1}$ of 202 was accepted if the organizational requirement of control is fulfilled.

During preparation of the mixture and molding processes, due to the environmental and financial reasons, it's impossible to make the calculated risk acceptable. Therefore the improvement activities based on the technological solution were undertaken. This kind of risk optimization aimed at prevention of the cause of incompatibility by the elimination of a threat, which the incompatibility creates. As the technological optimization manner the organization proposed the application of the crumbling machine processing the waste material qualified to the recycling. Such solution enabled for re-usage of the waste of molding process in the mixture preparation. Thus both the quantity of the produced waste creating the environmental risk (Table 1) and costs of the mixture (Table 2), defined as $\mathrm{IRR}_{2}$, were reduced. 
In the range of the system processes the application of the worked out methodology of system monitoring in the analyzed organization confirmed both the correctness of the implementation of the proposed risk system and its improvement from the moment of its initiation (Table 3).

System monitoring in the analyzed range of the risk management system proved the "zero level" - the worst one of system improvement. Traditionally realized integrated auditing reflected the minimal amount of incompatibilities. The used system analyzes confirmed on one hand the deficiency of the method being in the common practice, on the other hand the imperfection of the realized risk system processes and necessity of their improvement.

\section{Conclusions}

The integrated optimization of quality, environmental and occupational safety risk can be realized both by the system and technological solutions. In practice it requires the application of the univocal methods of different types of risk management. It should include the identification of different types of risk, classification of them, usage of the proper risk assessment methods, acceptability evaluation and undertaking the minimization activities.

In the author's methodology one has proposed the classification of operational and system risk and the adequate methods of the risk assessment. On the operational level the risk assessment is based on the quantitative methods using the Integrated Risk Ratio. In case of the system level one should apply the method of the risk monitoring. The acceptable value of the risk on the operational level, defined by the organization, should be reduced while improving the processes. The acceptable level of the system risk, appropriate for the category and dependent on its significance for the risk minimization, should be higher with the change of the risk system maturity.

Definition of the unacceptable risk values, both the system and the operational ones, should be a starting point for the risk minimization actions. Those activities can have the character of risk management system, the realization of processes in the supervised conditions during the operational control or, in the extreme circumstances, technological changes.

Practical implementation of the proposed risk management methodology in the chosen organization first of all has confirmed both its originality and effectiveness. Furthermore it has indicated the system and technological possibilities of integrated minimization of quality, environmental and occupational safety risk with the consideration of the costs of the optimization.

\section{References}

Bouder, F., Slavin, D., \& Löfstedt, R. E. (2007). A New Framework for Risk Management. London: Earthscan.

Ejdys, J. (2011). Model of improvement of standardized management systems based on the knowledge. Białystok: Technical University of Białystok.

Karkoszka, T. (2011). Estimation of processes realization risk as a manner of safety management in integrated systems. International Journal of Quality Research, 5, 131-141.

Karkoszka, T., \& Sokovic, M. (2012). Integrated risk estimation of metal insert gas (MIG) and metal active gas (MAG) welding processes. Metallurgy, 51, 179-182.

Kendall, R. (2000). Risk Management for Executives. Warsaw: Liber.

Kramer, M., Brauweiler, J., \& Nowak, Z. (2005). International Environmental Management. Tools and management systems. Warsaw: C.H. Beck.

Matuszak-Flejszman, A. (2010). Integration of management systems. In: Standardized management systems. Poznań: Economics University.

McDermott, R. E., Mikulak, R. J., \& Beauregard, M. R. (2000). The Basis of FMEA. New York: CRC Press.

Staniec, I., \& Zawiła-Niedźwiecki, J. (2008). Operational risk management. Warsaw: C.H. Beck.

Shewhart, W. A. (1986). Statistical method from the point of view of quality control. Mineola: Dover Publications.

PROBLEMS

OF MANAGEMENT

IN THE $21^{\text {st }}$ CENTURY

Volume 6, 2013

13 
Tatiana KARKOSZKA. Optimization of Quality, Environmental and Occupational Risk by the System and Technological Solutions

OF MANAGEMENT

IN THE $21^{\text {st }}$ CENTURY

Volume 6, 2013

Advised by Danuta Szewieczek, Silesian University of Technology, Poland

Received: February 02, 2013

Accepted: March 29, 2013

Tatiana Karkoszka

Ph.D., Eng., Assistant Professor, Institute of Engineering Materials and Biomaterials, Silesian University of Technology, Konarskiego 18a Street, 44-100 Gliwice, Poland.

E-mail: tatiana.karkoszka@polsl.pl

Website: http://www.polsl.pl 